\title{
Enhanced Aqueous Dissolution of a DNAPL Source to Characterize the Source Strength Function
}

\author{
Fang Wang ${ }^{1}$, Michael D. Annable ${ }^{1^{*}}$, Charles E. Schaefer ${ }^{2}$, Timothy D. Ault ${ }^{3}$, \\ Jaehyun Cho ${ }^{1,}$ James W.Jawitz ${ }^{4}$
}

1 - Department of Environmental Engineering Sciences, University of Florida, Gainesville, Florida 32611, United States

2 - Shaw Environmental \& Infrastructure, Lawrenceville, NJ 08648, United States

3 - CB\&I, Concord, CA 94520, United States

4 - Soil and Water Science Department, University of Florida, Gainesville, Florida 32611, United States

\footnotetext{
* Corresponding author address: Michael D. Annable, P.O. Box 116450, Gainesville, FL 32611-6450.

E-mail: annable@ufl.edu
} 


\begin{abstract}
Simplified analytical solutions, developed as source strength functions (SSFs), are capable of describing the temporal dissolution of nonaqueous phase liquids in groundwater, which is useful for predicting source longevity and can serve as a guide for remedial activities. Here, SSF parameters were estimated by fitting enhanced aqueous dissolution data from a flow cell consisting of three injection and four extraction wells to analytical dissolution models (power law model (PLM) and equilibrium streamtube model (EST)) at a trichloroethene (TCE) contaminated site, Alameda Point, California. Both the PLM and the EST model were able to characterize the observed aqueous TCE dissolution during enhanced water flooding. Additional field activities conducted at the site included soil core collection, a recirculated partitioning tracer test, passive flux meter transects, and push-pull tracer tests. The additional site characterization data were used to independently estimate the observed SSF parameters using information such as the TCE mass, distribution and porous media heterogeneity. The exponential decay model (a subset of the PLM) accurately predicted the enhanced dissolution, likely because the site was significantly aged (most of the mass in the plume rather than in the source zone) or middle stage, and the mass in the source zone could be approximately estimated. The EST tracerbased model, when combined with data from the recirculated partitioning tracer test, soil cores, and the push-pull tracer test, was capable of accurately predicting the observed aqueous dissolution. The mass in the source zone and the fraction of contaminated flowpaths were the most important site characteristics, requiring the greatest accuracy to predict aqueous dissolution. Establishing steady state dissolution was essential to provide a more accurate estimate of the fraction contaminated and high resolution data from soil cores in the source zone were needed to estimate the mass present.
\end{abstract}




\section{Introduction}

The dissolution of dense nonaqueous phase liquids (DNAPLs) into groundwater is a highly complex process due to the heterogeneous subsurface hydrogeolology and spatial DNAPL distribution (Christ, 2005; Dekker and Abriola, 2000; Fure et al., 2006; Parker and Park, 2004; Phelan et al., 2004; Unger et al., 1998). Complex numerical models are commonly used to simulate DNAPL dissolution dynamics, however, spatially variable aquifer and DNAPL characteristics that the numerical models require are not typically available. Simple analytical solutions that describe temporal DNAPL dissolution, known as source strength functions (SSFs), serve as a useful alternative and can provide valuable information such as the contaminant mass discharge from the source zone into the plume, longevity of the source and the corresponding evolution of the plume. The SSFs models have been developed by various researchers to describe mass flux (or mass discharge) changes over time (Basu et al., 2008a; Basu et al., 2008b; Christ et al., 2006; Christ et al., 2010; DiFilippo and Brusseau, 2008; Falta et al., 2005a; Falta et al., 2005b; Fure et al., 2006; Jawitz et al., 2003; Jawitz et al., 2005; Parker and Falta, 2008; Parker et al., 2010; Parker and Park, 2004; Zhu and Sykes, 2004). These models are simple compared to complex multiphase flow and transport simulations, and can be used to predict long-term effects of source depletion efforts. All the models, though different in their conceptualization, include two basic parameters that describe the mean DNAPL mass and the joint variability in the velocity and DNAPL distributions (Basu et al., 2008b).

These SSFs include the equilibrium streamtube model (EST) and the power law model (PLM). While other models exist (Parker and Park, 2004), these two were the primary focus of this study. The EST model is based on a Lagrangian approach where the DNAPL source zone is conceptualized as a collection of non-interacting streamtubes, with hydrodynamic and DNAPL 
heterogeneity represented by the variation of the travel time and DNAPL saturation among the streamtubes (Jawitz et al., 2003; Jawitz et al., 2005). For the EST model, this is encapsulated in the expression for the time-varying dissolved concentration from the source zone:

$$
C(t)=\frac{1}{2} f_{c} C_{s}\left[1-\operatorname{erf}\left(\frac{\ln t-\mu_{\ln \tau}}{\sigma_{\ln \tau} \sqrt{2}}\right)\right]
$$

where $C(t)$ is the flux-averaged concentration leaving the source zone; $f_{c}$ is the fraction of the streamtubes initially containing DNAPL; $C_{s}$ is the solubility limit of the DNAPL in water; $\tau$ is defined as reactive travel time that combines the travel time $t$ and the trajectory-averaged DNAPL content $\hat{S}\left(\hat{S}=\frac{\hat{S}_{N} \eta}{\theta_{w}}\right.$, where $\hat{S}_{N}$ is the trajectory-averaged DNAPL saturation along a streamline, $\eta$ is the porosity, and $\theta_{w}$ is the water content); $\mu_{\ln \tau}$ and $\sigma_{\ln \tau}$ are the mean and standard deviation of the $\log$ normal variable $\ln \tau$. The travel time $t$ and the DNAPL content $\hat{S}$ are both assumed to be lognormal variables, so the reactive travel time also follows the lognormal distribution.

Studies have shown that the EST model is capable of accurately predicting DNAPL dissolution by using partitioning tracer tests to independently parameterize the model. These studies include Chen and Jawitz (2008) based on laboratory experiments, Basu et al. (2008a) based on UTCHEM model simulations, and Wang et al. (2013) based on field datasets. In order to parameterize Equation 1, the required data include initial aqueous concentration, and nonpartitioning and partitioning tracer breakthrough curves. The initial aqueous concentration is used to estimate $f_{c}$ by scaling to the DNAPL solubility limit. The nonpartitioning and partitioning tracer data should be complete and show adequate separation (retardation factor $\mathrm{R}>1.2$ as suggested by Jin, 1995). In order to estimate EST model parameters using short 
duration tracer tests, that can be used to predict long term behavior of the source zone, equilibrium dissolution is assumed. The scale of the tracer swept volume must also be representative of the entire source zone (Basu et al., 2008a; Wang et al., 2013).

The PLM presented by Falta et al. (2005b) and Zhu and Sykes (2004) is modified using $f_{c} C_{s}$ to replace $C_{0}$ (initial concentration) in order to be consistent with the EST model,

$$
C(t)=f_{c} C_{s}\left[\frac{(\Gamma-1) f_{c} C_{s} V_{d} A}{M_{0}} t+1\right]^{\frac{\Gamma}{1-\Gamma}}
$$

where $\Gamma$ is a PLM fitting parameter; $V_{d}$ is the Darcy velocity; $A$ is the cross-sectional area through which contaminants migrate; and $M_{0}$ is initial mass in the source zone. The special case of $\Gamma=1$ leads to a simple exponential form for the source zone concentration over time (Zhu and Sykes, 2004),

$$
C(t)=f_{c} C_{s} \exp \left(-\frac{f_{c} C_{s} V_{d} A}{M_{0}} t\right)
$$

In laboratory experiments, Chen and Jawitz (2009) found that dissolution follows an exponential decay at aged contaminated sites where an appreciable fraction of the initial DNAPL mass has been eluted but a small fraction of DNAPL remains in the source zone.

For the EST model, partitioning tracer tests can be used to estimate the parameters $\mu_{\ln \tau}$ and $\sigma_{\ln \tau}$ (Basu et al., 2008a; Chen and Jawitz, 2008; Wang et al., 2013). However, if tracer test data are low quality or incomplete, other site characterization data such as soil cores, multilevel samplers (MLSs) (Kubert and Finkel, 2006), passive flux meters (PFMs) (Annable et al., 2005; Hatfield et al., 2004), and push-pull tracer tests (Schroth et al., 2000), may be useful to supplement the tracer data. For the PLM, the parameter $\Gamma$ must be obtained by fitting the model to DNAPL dissolution data sets since it is an empirical function parameter and does not have 
physical meaning (Basu et al., 2008b; Johnston et al., 2013). Aqueous dissolution data sets with a longer time series near a source zone are very useful because they directly reflect the source strength and can be fitted using SSFs. However, this type of data is often not available and would require significant costs and a longer time frame to collect under natural gradient flow conditions due to the typically low groundwater flow velocity. Therefore, forced gradient flows are often used to enhance dissolution by increasing flow rate (Johnston et al., 2013).

This study estimated SSF parameters by fitting enhanced dissolution data at a field site to Equations 1 and 2. Source mass was estimated using four different methods: 1) soil core data combined with membrane interface probe (MIP) data to delineate the extent of the DNAPL, 2) partitioning tracer data recovered in the extraction wells, 3) tracer and aqueous dissolution data during a push-pull tracer test based on EST model theory, and 4) normalized peak concentration differences between nonpartitoning tracers and partitioning tracers. Combining the estimated mass with the enhanced dissolution during the push-pull tracer test, the EST parameters were independently estimated and used to predict dissolution for comparison to the enhanced dissolution data. For the PLM, $\Gamma=1$ was assumed and the predicted dissolution was compared with the enhanced dissolution data. Estimated SSF parameters were used to predict six months of dissolution that occurred under natural gradient conditions following enhanced dissolution and was compared with PFM data. Guidance was provided on what types of data are most valuable for charactering SSF parameters.

In this study, Alameda Plume 4-1 was selected because the site offered a relatively small, shallow DNAPL source area with adequate initial definition for conducting enhanced aqueous dissolution. The relatively easy access to the DNAPL source provided the opportunity to conduct field activities including core sampling, a partitioning tracers test, push-pull tracer tests, 
groundwater samples from multilevel samplers, and application of passive flux meters before and after the enhanced aqueous dissolution. More details on this site are provided in the following section.

\section{Methods}

\subsection{Field Site Background}

The Plume 4-1 site is in Operable Unit 2B, Installation Restoration site 4, Alameda Point, located on the western tip of Alameda Island, along the eastern margin of San Francisco Bay, California. Plume 4-1 appears to be the result of a surface release near the intersection of a former railroad spur and Skyhawk Street that has led to high concentration in the shallow surficial aquifer of VOCs including trichloroethene (TCE), 1,1-dichloroethene (1,1-DCE), cis1,2-dichloroethene (cis-1,2-DCE), trans-1,2-dichloroethene (trans-1,2-DCE), 1,1-dichloroethane (1,1-DCA) and 1,1,1-trichloroethane (1,1,1-TCA). The main contaminant is TCE, and the other VOCs have relatively low concentrations. The reported concentration of dissolved TCE used in this study includes degradation products (dichloroethylene, vinyl chloride, and ethene) that were converted into equivalent concentrations of TCE.

\subsection{Site Conceptual Model}

During the initial phase of this study, several field activities were conducted to further delineate the DNAPL source zone and aquifer permeability. Using historical groundwater data as a preliminary guide, membrane interface probes (MIPs) were used to provide an initial estimate of the lateral and vertical extent of potential DNAPL source (square area in Figure 1). Soil cores (direct push cores (DPCs) in Figure 1) coupled with photoionization detection (PID) were collected for soil TCE analysis in the suspected source zone to further verify and quantify the presence and vertical distribution of DNAPL. A hydraulic profiling tool (HPT) was used to 
obtain a high-resolution vertical profile of the permeability distribution. The data from the MIPs, soil cores and HPT provided information to construct a basic two-zone site conceptual model: a low-flow zone $4.6 \mathrm{~m}$ to $6.1 \mathrm{~m}$ below ground surface (bgs) composed of $85 \%$ sand and $15 \%$ silt, and a high-flow zone $6.1 \mathrm{~m}$ to $7.6 \mathrm{~m}$ bgs consisting of sand.

The site age is considered middle stage (ITRC 2011) because it has a large plume and DNAPL remaining in the source zone. The plume area to source zone area ratio was $265: 1$, and both Sudan IV dye screening and soil core solvent extractions (Stafford et al., 2009) showed existing DNAPL in the source zone. This study focused on DNAPL dissolution as the dominant source of mass discharge from the source zone recognizing that matrix diffusion may also contribute to mass discharge.

\subsection{Source Zone Characterization}

Passive flux meters (PFMs) (Annable et al., 2005; Hatfield et al., 2004) were installed into wells SPW-1, SPW-2, SPW-3-1, SPW-3-2 and SPW-4 with the screen intervals in both the low-flow and high-flow portions (Table 1) in the source zone in June 2010 with a vertical sampling resolution of $15 \mathrm{~cm}$. At the same time, MLSs were installed at locations MLS-1 to MLS-8 with a vertical sampling interval $0.30 \mathrm{~m}$ focused on the low-flow zone (Table 1).

A push pull tracer test (Schroth et al., 2000) was conducted in August 2010 in two wells within the suspected source zone (SPW-3-1 and SPW-4) and one well (MW1A1) in the plume (Figure 1). For SPW-3-1 and SPW-4, the well diameter was $3.8 \mathrm{~cm}$ with no gravel pack, while the well diameter for MW1A1 was $5.1 \mathrm{~cm}$ with $10 \mathrm{~cm}$ gravel packing (see Table 1). In the push pull tracer test, methanol $\left(C_{0}=530 \mathrm{mg} / \mathrm{L}\right)$ and isopropyl alcohol (IPA, $\left.C_{0}=1050 \mathrm{mg} / \mathrm{L}\right)$ were used as nonpartitioning tracers, and n-hexanol $\left(C_{0}=470 \mathrm{mg} / \mathrm{L}\right), 2$,4-dimethyl-3-pentanol (DMP, $\left.C_{0}=540 \mathrm{mg} / \mathrm{L}\right), 2$-ethyl-1-hexanol (e-HEX, $\left.C_{0}=130 \mathrm{mg} / \mathrm{L}\right)$ and 1-octanol $\left(C_{0}=130 \mathrm{mg} / \mathrm{L}\right)$ were 
used as partitioning tracers (see Table 2). A volume of $0.21 \mathrm{~m}^{3}$ of tracer solution was injected into each well over 8 hours with an estimated tracer penetration diameter of $1.1 \mathrm{~m}$, and recovered over a period of 2.5 days with average pumping rates of $0.90 \mathrm{~m}^{3} / \mathrm{day}, 0.55 \mathrm{~m}^{3} /$ day and 0.71 $\mathrm{m}^{3} /$ day for SPW-3-1, SPW-4 and MW1A1, respectively.

Soil cores were collected in November 2010 at locations SIW-02, MLS-1, MLS-2 and PEW-03 at depths with high concentration indicated by screening level PID signals. Groundwater samples were collected in all the wells in the source zone in December 2010. PFMs were installed in the transect formed by PEW-01 04 and mass/Darcy flux were measured in February 2011.

A recirculating partitioning tracer test (PTT) and enhanced aqueous dissolution test were conducted during the period of April to May 2011 for approximately 37 days. The PTT was conducted during the early phase of the enhanced aqueous dissolution test. The injection wells were SIW-01, SIW-02 and SIW-03 with injection rates of $4.85 \mathrm{~m}^{3} /$ day, and the extraction wells were PEW-01, PEW-02, PEW-03 and PEW-04 (Figure 1) with pumping rates of $4.04 \mathrm{~m}^{3} / \mathrm{day}$. The vertical screen intervals for the injection wells were located in both the low-flow and highflow zones (Table 1). In the PTT, methanol $\left(C_{0}=430 \mathrm{mg} / \mathrm{L}\right)$ and IPA $\left(C_{0}=1000 \mathrm{mg} / \mathrm{L}\right)$ were used as nonpartitioning tracers, and n-hexanol $\left(C_{0}=380 \mathrm{mg} / \mathrm{L}\right), 2$-octanal $\left(C_{0}=120 \mathrm{mg} / \mathrm{L}\right)$ and e-HEX $\left(C_{0}=120 \mathrm{mg} / \mathrm{L}\right)$ were used as partitioning tracers with a tracer injection duration of 0.45 days (see Table 2). Tracer effluent from extraction wells was displaced through an activated carbon drum and then reinjected (only methanol and IPA were detected in the activated carbon efluent). During the PTT, multilevel sampling was conducted at locations MLS-1 through 8, with the sampling focused primarily in the low-flow zone (Table 1). Concentrations of tracers and aqueous TCE were measured. Groundwater samples were collected at locations MLS-1 through 
8 approximately 5 months after the enhanced aqueous dissolution was completed. PFMs were deployed in the four extraction wells PEW-01 04 approximately six months after the end of the enhanced dissolution test. Bioaugmentation was conducted 16 months after the enhanced dissolution, but the results are not included in this study.

The injected tracer concentrations were chosen based on a linear partitioning relationship between TCE and water. The measured values of partitioning coefficient $\mathrm{K}_{\mathrm{N}}$, determined using batch equilibrium methods with TCE collected from the site (e.g., Jawtiz et al., 2000), for all the tracers are shown in Table 2.

\subsection{DNAPL Volume Estimates}

The volume of contaminant is rarely known at DNAPL contaminated sites. However, an estimate of the volume is essential to accurately estimate SSF parameters. The most frequently used technique is collection and analysis of soil samples from soil cores (Feenstra, 2003). Using partitioning tracers is another method to estimate the DNAPL volume (Annable et al., 1998; Basu et al., 2008a; Brooks et al., 2002; Cain et al., 2000; Falta et al., 1999; Jawitz et al., 2003; Jawitz et al., 2000; Jin et al., 1995; Meinardus et al., 2002; Nelson and Brusseau, 1996; Ramsburg et al., 2005). Geophysical methods may also be applied to locate the DNAPL distribution and estimate the source volume (Brewster et al., 1995). Here, four different methods were used to estimate the volume of DNAPL in the source.

\subsubsection{Method 1: Soil core data combined with MIP data}

The MIP data were used to approximately delineate the suspected source zone (square in Figure 1) (Bronders et al., 2009; Nadolishny and Fraser, 2001) at a depth between $5.2 \mathrm{~m}$ and 6.7 m bgs. Soil cores SPW-3-2 and DPC-15 had very high TCE concentration at depths from $5.6 \mathrm{~m}$ to $6.7 \mathrm{~m} \mathrm{bgs}(2200 \mathrm{mg} / \mathrm{kg}$ at the depth of $5.8 \mathrm{~m}$ in SPW-3-2 and $6600 \mathrm{mg} / \mathrm{kg}$ at the depth of 6.1 
in DPC-15), while concentration in other soil cores were below $100 \mathrm{mg} / \mathrm{kg}$ at all sampling depths indicating no DNAPL present. MIP-7, close to SPW-3-2 and DPC-15, also showed a high PID signal at the same depth intervals agreeing with the cores. MIP-2, 6, 9, 10 and 11 (see Figure 1) showed no significant evidence of contaminants, while the PID signals for MIP-3 and MIP-7 were high (more than $2 \times 10^{6} \mathrm{mV}$ ) between $5.2 \mathrm{~m}$ to $6.7 \mathrm{~m}$ bgs. Soil core SPW-3-2 had high TCE concentration between depths $5.6 \mathrm{~m}$ to $6.1 \mathrm{~m}$ bgs indicating DNAPL present (estimated as greater than $100 \mathrm{mg} / \mathrm{Kg}$ ). Groundwater samples collected from the MLS network were consistent with MIP and soil core data and indicated that DNAPL sources were likely present in the lowflow zone (4.6 $\mathrm{m}$ to 6.1 ) identified using the HPT. Based on this information, an approximate minimum (yellow circle area in Figure 1) and maximum (square area in Figure 1) extent of the DNAPL mass was delineated and the DNAPL volume was determined as

$$
V_{N}=\rho_{b} V_{\text {soil }} \bar{C} / \rho_{T C E}
$$

where $\rho_{b}$ is soil bulk density $\left(1.67 \times 10^{3} \mathrm{~kg} / \mathrm{m}^{3}\right.$ assumed $), \rho_{\text {TCE }}$ is TCE density, $V_{\text {soil }}$ is volume of soil, $\bar{C}$ is average concentration based on the entire high resolution soil core profile at SPW-3-2 $(\mathrm{mg} / \mathrm{kg})$. Note that the TCE concentrations within the minimum and maximum extent were assumed the same as the average concentration at SPW-3-2.

\subsubsection{Method 2: PTT tracer breakthrough curves}

This method used the entire PTT data to estimate the average TCE saturation in the swept volume based on the separation between two tracers that had different partitioning coefficients (Annable et al., 1998; Jin et al., 1995).

For the PTT, the recovered effluent with tracers was pumped through activated carbon drums and then re-injected. The observed concentration of the nonpartitioning tracers during the breakthrough curve tailing showed increases which likely represented breakthrough of tracers 
that were reinjected after passing through the activated carbon drum. In contrast, the partitioning tracers, 2-octonal and n-hexanol, did not pass through the activated carbon drums and were not impacted by recirculation, thus, this pair was used to estimate the DNAPL mass. The average saturation of TCE in the source zone can be estimated from the first normalized moments of the two partitioning tracers,

$$
\bar{S}_{N}=\frac{R-1}{K_{N, 2}-1-R\left(K_{N, 1}-1\right)}
$$

where the retardation factor, $R$, is the ratio of the first normalized moment of the partitioning tracers and $K_{N}$ is the tracer TCE-water partitioning coefficient. The total DNAPL volume, $V_{N}$, within the swept volume of each well was determined by as the product of the average $\bar{S}_{N}$ and the swept volume $V_{S}$, determined for each well. The first moment of the n-hexanol tracer data was used since it has a lower $K_{N}$ and avoids the high uncertainties and complications using the recirculated methanol or IPA.

\subsubsection{Method 3: Push-pull tracer tests}

The separation between partitioning and nonpartitioning tracers for the push-pull tracer test was not distinct enough to directly estimate the DNAPL mass using previously applied methods (Schroth et al., 2000). An alternative approach was applied where the push-pull nonpartitioning tracer data (IPA) and contaminant dissolution data were scaled to have comparable relative concentrations

$$
\begin{gathered}
\bar{C}_{n p}=1-\frac{C_{n p}}{C_{0-n p}} \\
\bar{C}=\frac{C}{C_{p e a k}}
\end{gathered}
$$


where $\bar{C}_{n p}$ is the normalized nonpartitioning tracer concentration, $C_{n p}$ is nonpartitioning tracer concentration during the push-pull tracer test, $C_{0-n p}$ is input tracer concentration, and $\bar{C}$ is TCE concentration $C$ scaled to the maximum concentration $C_{\text {peak }}$ during the push-pull tracer test.

Separation between scaled nonpartitioning tracer data and TCE concentration data indicates the presence of DNAPL in the tracer swept zone and potentially can be used to estimate the mass in the source zone. First the scaled nonpartitioning tracer data was fit using Equation 1 to determine $\mu_{\ln t}$ and $\sigma_{\ln t}$ by assuming no DNAPL $\left(\mu_{\ln \tau}=\mu_{\ln t}, \sigma_{\ln \tau}=\sigma_{\ln t}\right)$, and the first moment of the $t$ distribution $m_{1}^{t}$ was calculated as

$$
m_{1}^{t}=\exp \left(\mu_{\ln t}+\frac{\sigma_{\ln t}^{2}}{2}\right)
$$

The peak scaled TCE dissolution data was fitted using Equation 1 to determine $\mu_{\ln \tau}, \sigma_{\ln \tau}, f_{c}$ and then used to calculate the first moment of the $\tau$ distribution $m_{1}^{\tau}$ using equation 8 with $\tau$ substituted for $\mathrm{t}$.

Then, the first moment of the $\hat{S}$ distribution $m_{1}^{\hat{S}}$ was calculated as (Basu et al., 2008a; Jawitz et al., 2003)

$$
m_{1}^{\tau}=K_{w} m_{1}^{t} m_{1}^{\hat{S}}
$$

where $K_{w}=\rho_{T C E} / C_{s}$. The swept volume of the push-pull test was smaller than the source zone volume, but in this estimation, the same TCE distribution was assumed outside and within the push pull swept volume as in the source zone. Finally, the volume of DNAPL in the source zone was estimated using, 


$$
V_{N}=f_{c} V_{S Z} m_{1}^{\hat{S}}
$$

where $V_{S Z}$ is the source zone volume (square in Figure 1) which is different from the swept volume $V_{S}$.

\subsubsection{Method 4: PTT peak concentration}

It is often difficult to obtain temporal moments due to limited sampling and concentrations below the detection limit particularly at early and late times. Peak concentration is generally easier to obtain, and peak arrival time has been used to infer hydrogeological parameters (Bellin and Rubin, 2004). Here, temporal MLS data were limited at late times, but tracer peak concentration was captured. The normalized peaks of the nonpartitioning tracer BTCs were higher than those of the partitioning tracer BTCs and the peaks appeared to elute at about the same time at both MLSs and extraction wells. The reduction in peak height of the partitioning tracers is not believed to be due to tracer degradation based on laboratory batch partitioning tests, and may be attributed to partitioning of tracer into DNAPL as would occur in a simple batch reactor. Here, a simple linear partitioning isotherm was assumed to partition tracer between the volume of water and volume of DNAPL in the MLS flow path as if the system behaved as a batch reactor. Based on the linear partitioning relationship between the NAPL and water phases, and mass balance of both nonpartioning tracer (methanol) and partitioning tracers (2-octonal), the NAPL volume was derived,

$$
V_{N}=\frac{\frac{C_{n p-w}}{C_{0-n p}}-\frac{C_{p-w}}{C_{0-p}}}{K_{N} \frac{C_{p-w}}{C_{0-p}}} V_{w}=\bar{S}_{N} V_{w}
$$


where $C_{p-N}$ and $C_{p-w}$ are tracer concentrations in the DNAPL and aqueous phase, $M_{p-T}$ is the total partitioning tracer mass, $M_{n p-T}$ is total nonpartitioning tracer mass, $V_{w}$ and $V_{i n}$ are volume of water and tracer input volume, respectively. For each MLS tracer data point, $V_{w}$ was estimated using the upgradient volume from the injection well plane (SIM-01, SIM-02 and SIM03) to the downgradient MLS locations (SMLS-4, 7 and 8) weighted by the space between samplers and sampling depths. For the tracer recovery in the extraction wells, $V_{w}$ is the same as the swept volume $V_{S}$, which was estimated by the first moment of the n-hexanol data. The tracers used here were methanol and n-hexanol since these data showed clear peaks both the recovery wells and the MLSs. This approach was adopted for the MLS network because data from these locations were potentially much more sensitive to DNAPL present in the low flow zone.

\subsection{SSF estimates based on aqueous dissolution data}

Increased flow velocity during the injection and pumping process may lead to nonequilibrium dissolution. However, studies have shown a field scale effective mass transfer coefficient used to describe the dissolution is insensitive to flow velocity changes, while localscale mass transfer is a function of flow velocity and becomes important at later times (Basu et al., 2008a; Basu et al., 2008b; Page et al., 2007; Parker and Park, 2004). Moreover, limited rebound was observed for the aqueous TCE concentration following the enhanced dissolution. Thus, dissolution in the source zone is assumed to be an equilibrium process.

The time required to reach steady state capture was estimated based on the method presented by Yang et al. (1995). In this method, the location of a stagnation point is calculated under the imposed flow pattern and an analytical solution is used to estimate the time required to 
approach steady state flow. Only concentration data later than the capture time was used for subsequent model fits.

The contaminated fraction $f_{c}$ (Equation 1 and 2) was estimated by the initial aqueous TCE concentration after the capture time had been reached divided by the solubility limit (Basu et al., 2008a; Chen and Jawitz, 2008; Jawitz et al., 2003). Mass discharge was calculated by measured concentration multiplied by the pumping rate, and was subsequently fitted using Equation 1 employing a genetic algorithm method developed by Wood (2011) to determine the parameters $\mu_{\ln \tau}$ and $\sigma_{\ln \tau}$. Note that Equation 1 was converted into a mass discharge form by multiplying by the pumping rate. Equations $8 \mathrm{~b}, 9$, and 10 were used to estimate the NAPL volume $V_{N}$ in the source zone. Note that $V_{s}$ replaced $V_{S Z}$ in Equation 10 since the estimated NAPL saturation $m_{1}^{\hat{S}}$ from Equation 9 is the average NAPL saturation in the contaminated swept volume $V_{s}$ which is different from the source zone volume $V_{S Z}$. The PLM was also used to fit the mass discharge data using the genetic algorithm method. The initial mass $M_{0}$ was estimated directly by fitting.

\subsection{SSF estimates based on site characterization data sets}

For the PLM, the parameter $\Gamma$ has no physical meaning and can be estimated through fitting the model to data. This estimation is very challenging if there are no enhanced aqueous dissolution data. However, since the site age is appreciably aged, the parameter $\Gamma=1$ may be a reasonable assumption (Chen and Jawitz, 2009). Initial mass $\mathrm{M}_{0}$ can be estimated by following the methods provided in section 2.4.

For the EST, there are two parameters $\mu_{\ln \tau}$ and $\sigma_{\ln \tau}$ to estimate. The parameter $\sigma_{\ln \tau}$ can be usually estimated by partitioning tracer test data (Basu et al., 2008a; Chen and Jawitz, 2008; 
Jawitz et al., 2003; Wang et al., 2013) or can be replaced approximately by $\sigma_{\ln t}$ as swept volume is much larger compared to the volume of NAPL (Johnston et al., 2013). However, since the second moment is required, high quality tracer data, particularly in the tailing portion of the breakthrough curve, are necessary, which were not available at this site. Here, we have high quality TCE dissolution data during the push-pull tracer test and $\sigma_{\ln \tau}$ was estimated by fitting the TCE data to Equation 1 under the assumption that the aquifer and TCE heterogeneity in the swept volume of the push-pull tracer test represent conditions in the entire source zone. After inserting the volume estimated in Section 2.4 into Equation 10, the first moment of the $\hat{S}$ distribution, $m_{1}^{\hat{S}}$, was estimated. Then using Equation 9, the first moment of reactive travel time $m_{1}^{\tau}$ was estimated. Finally, Equation $8 \mathrm{~b}$ was used to determine the parameter $\mu_{\ln \tau}$.

\section{Results and Discussion}

\subsection{Site characterization and PTT}

High TCE concentrations were detected from $5.8 \mathrm{~m}$ to $6.1 \mathrm{~m}$ bgs in the soil core SPW-32 with a vertical resolution of $7.6 \mathrm{~cm}$. The PID signals from MIP-7 near SPW-3-2 and SPW-3-1 were high at a similar depth interval form $5.5 \mathrm{~m}$ to $6.4 \mathrm{~m}$ bgs (Figure 2). Additionally, higher pressure was detected from an HPT located in the source zone at the same depth indicating the presence of a low-flow zone (Figure 2). During the push-pull tracer tests, the recovery of dissolved TCE concentrations in Well SPW-3-1 (Figure 3) was relatively rapid compared to that observed at well MW1A1 which was located in the down gradient plume and had no evidence of DNAPL present locally. At well MW1A1, the mean travel time for both nonpartitioning tracer and the dissolved TCE was close to the time when the injected water during the push-pull was recovered (vertical dashed line in Figure 3 for MW1A1), indicating no NAPL in the tracer swept zone around MW1A1. In contrast, at well SPW-3-1, the mean travel time for the dissolved TCE 
was earlier than the time when the injected water was recovered (vertical dashed line in Figure 3 for SPW-3-1), indicating NAPL within the swept volume of the push-pull test and dissolution during the test.

Average pore water velocities were estimated based on the PTT nonpartitioning tracer (methanol) peak arrival time at MLSs (Figure 4). The data indicate a contrast between low- and high-velocity zones at a depth of about $5.9 \mathrm{~m}$ bgs which is consistent with the conceptual model based on MIPs, soil cores and HPT data. After exponential extrapolation (e.g. Annable et al., 1998;), the separation of $n$-hexanol and 2-octanol for the flow weighted average of all the extraction wells, PEW-T, was observed (Figure 5).

\subsection{Source DNAPL volume estimates}

Method 1 used soil core and MIP data around the source zone. In this approach the minimum and maximum TCE extent were delineated and the estimated DNAPL volume ranged from $2.0 \mathrm{~L}$ to $20 \mathrm{~L}$ in the source zone. This method provided a wide but reasonable range of mass in the source zone (Table 3) compared with the mass estimated directly using the enhanced dissolution data in the next section.

Method 2 used the PTT tracer concentration data (n-hexanol and 2-octanol) in the four extraction wells. The mass recoveries for n-hexanol and 2-octanol were low (54\% and 52\%, respectively) but the BTCs did show separation (Figure 5). Contributing factors leading to low recovery include no hydraulic control wells and a weak natural gradient. This method yielded an estimated $11 \mathrm{~L}$ of TCE in the tracer swept zone with an overall $\mathrm{R}=1.06$ (Table 3). The retardation factor is low because the average DNAPL saturation was low $\left(2.3 \times 10^{-4}\right)$ in the total swept volume $V_{s}$ of $49 \mathrm{~m}^{3}$. The well with the largest estimated volume was PEW-2, with 5.8 L and $\mathrm{R}=1.12$. This method may have higher uncertainties (estimated $\pm 30 \%$ ) because the 
retardation factors were lower than 1.2 , which is the minimum value suggested by Jin et al. (1995). The early peak of tracer observed at the extraction wells may be primarily responding to the high-flow zone present at the site while the distal portion of the breakthrough was a combination of tracer from both zones. Based on the pore velocity contrast between zones (Figure 4) and the tracer separation in the tailing part of the break though, the tracer volume estimate likely included DNAPL mass in both zones.

Method 3 estimated average saturation in the source zone $\bar{S}_{N}=f_{c} m_{1}^{\hat{S}}=3.0 \times 10^{-4}$ which is slightly higher than that in method 2 , but $V_{s}$ is only one fourth of the value used in method 2 since the screen interval for SPW-3-1 was much shorter than the PEWs $(0.7 \mathrm{~m}$ versus $3 \mathrm{~m}$, Table 1). As a result, 3.7 L of DNAPL was estimated. The swept volume of the push-pull tracer test conducted was smaller than the source zone $\left(2.3 \mathrm{~m}^{3}\right.$ versus $\left.12 \mathrm{~m}^{3}\right)$, thus, the mass may not be representative of the entire source zone area.

Method 4-1 used normalized peak concentration of the extraction well data producing a DNAPL estimate of 9.9 L. Application of the same method to the MLS data, method 4-2, resulted in an estimate of 37 L of DNAPL, which was much higher than all other estimates. There are two possible explanations for the different results. Since methods 4-1 and 4-2 both used only normalized peak differences and the swept volume for the extraction wells containing both the low and high-flow zones, as mentioned before, it is likely that the normalized peak differences from the extraction wells were primarily responsive to the high-flow zone where a smaller volume of NAPL was present, while method 4-2 reflected DNAPL in the low-flow zone since MLS were located in that zone. As a result, method 4-1 potentially underestimated the total volume. The other possibility is that the method method 4-2 potentially overestimated the mass due to localized mass around MLS-4, 7 and 8 which produced larger peak differences, between 
the nonpartitioning tracer and partitioning tracer. The point locations may not be representative of the entire source zone. It is important to note that without the MLS PTT data, the volume of DNAPL in the low flow zone may not have been detected by the integral partitioning tracer method.

The volumes estimated by the four methods provide a range of values for consideration in dissolution prediction. The volume based on method 2 in PEW-02 and PEW-04 were the largest and smallest, respectively, within the swept volumes of the four extraction wells and were consistent with using method 4-1 for PEW-02/PEW-04 and method 4-2 for MLS-4/MLS-8 which were located near PEW-02 and PEW-04.

\subsection{SSFs based on enhanced dissolution data sets}

To assess whether the enhanced dissolution data collected in the extraction wells was representative of both the low-flow and high flow zones, the MLSs aqueous TCE concentrations during the enhanced dissolution test were analyzed using a Kriging interpolation method in Surfer (Figure 6). Comparing the first two concentration distribution lots which represent a difference of one week during the water flood, concentration decreased at the upgradient MLS-1, but increased at downgradient MLS-7 indicating flow from upstream to downstream. The concentration from the later contour plots also decreased with time due to water flushing through the low flow zone. This supports loss of mass from the low flow zone rather than dissolution predominantly form the high-flow zone. Additionally, Figure 6 shows there was TCE concentration rebound at MLS-1 following enhanced dissolution. The percent of the total mass discharge emanating from the low-flow zone was estimated at $67 \%$ based on the transect composed by MLS-4, MLS-7 and MLS 8 and using those samplers located in the low-flow zone. 
This indicates that the water flushing duration was adequate to capture significant dissolution of mass from the low-flow zone.

The aqueous concentration of TCE dropped rapidly at the beginning of water recirculation (see Figure 7) potentially due to a transition to steady state contaminant transport. The capture time was estimated to be 2.64 days based on the method of Yang et al. (1995).

The mass discharge $M_{D}$ was calculated and fitted using Equation 1 and 2 employing the genetic algorithm method developed by Wood (2011) and the results are provided in Tables 4 and 5, and Figure 8. The PEW-total is the sum of mass discharge for all four extraction wells. Both models fit the mass discharge data well with the Nash-Sutcliffe model efficiency coefficient $E>0.8$, except PEW-04. A genetic algorithm best fit could not be obtained for well PEW-04 and the fit shown was manually determined by trial and error. DNAPL volume estimates from the previous section indicated that there was limited mass within the PEW-04 swept volume. The site average $\Gamma$ value was around 1 and thus, based on Chen and Jawitz (2009), may be representative of a middle stage site. The low value for $f_{c}=0.01$ ( $1 \%$ of the swept volume has NAPL), suggests that the swept zone for the four extraction wells, including the vertical screen interval of $3 \mathrm{~m}$, were inefficient for targeting the relatively small DNAPL source within the low-flow zone. Short circuiting of flow through the high-flow zone may still have occurred even if the screen intervals had been placed only across the low-flow zone.

There was $11 \mathrm{~L}$ of TCE in the source zone estimated from the DNAPL volume sum of the four individual extraction wells from volume estimation method 1 , and the same amount of TCE was also found from fitting the EST model to PEW-total. For the PLM, a DNAPL volume of 7.7 L was estimated from the volume sum of four individual extraction wells and $7.8 \mathrm{~L}$ from 
the single PEW-total fitting. The DNAPL volume estimated from PLM is lower than from the EST model, but comparable.

\subsection{SSFs based on site characterization data}

The parameters of the SSFs can be estimated following the procedure outlined in section 2.6 combining DNAPL volume estimated in section 2.4 to predict aqueous TCE dissolution. The EST model parameters $f_{c}=0.01, \sigma_{\ln \tau}=1.4$, and $\mu_{\ln \tau}=2.43,2.73$ and 4.29 correspond to $2.0 \mathrm{~L}, 11 \mathrm{~L}$ and 20L DNAPL volumes, respectively. The prediction results are provided in Figure 9 for the DNAPL volumes of 2.0 L, 11L and $20 \mathrm{~L}$ for both EST and PLM (special case $\Gamma=1$ ). The lowest and highest of these DNAPL volumes under- and over-estimated the observed dissolution, while the 11 L estimate accurately predicted the dissolution in both the PLM and EST model. Thus, quantifying the volume located in the source zone is critical to predict aqueous dissolution. If $f_{c}$ were estimated using the concentration observed during the early transient flow condition (see Figure 7) or before the PTT, the value of $f_{c}$ would be overestimated and thus, the SSF prediction would be overestimated.

\subsection{TCE dissolution prediction following enhanced mass removal}

The estimated EST and PLM parameters were used to predict natural gradient TCE dissolution following enhanced mass removal study. The predicted TCE mass discharge either for the EST or PLM 11 L case models, after about six months, was significantly overestimated compared to the measured PFM data collected in PEWs (square symbol in Figure 9). This was potentially due to enhanced bioremediation stimulated by the water flood since higher concentrations of degraded forms of TCE were observed in the PFM data. Three months before the enhanced dissolution study, there was limited degradation byproducts present and the calculated mass discharge based on PFMs in PEWs was slightly higher than that at the beginning 
of the enhanced dissolution (Figure 9). Water samples were collected at 16 months after the end of the enhanced dissolution study, prior to the bioaugmentation study. The concentrations in the PEWs was within 5\% of concentrations predicted using the EST or PLM models with $11 \mathrm{~L}$ of DNAPL. This suggests that the source zone may have been disturbed by the enhanced dissolution study and had not recovered during the PFM deployment conduct after only 6 months.

It is important to recognize that mass discharge from PFMs conducted under natural gradient flow before and after the enhanced dissolution was scaled up to match and provide a direct comparison with the enhanced dissolution mass discharge. The average Darcy velocity during the enhanced dissolution in the lower permeability zone was about 11.5 times higher than that under natural gradient conditions. Thus, for the EST $11 \mathrm{~L}$ case model, an estimated 6 years (about 40 pore volumes) of natural gradient flow would be required for the source mass to decrease by an additional $4 \mathrm{~L}$ in the absence of biodegradation.

\section{Conclusions}

Both the EST and the PLM have the ability to describe aqueous dissolution from DNAPL source zones. The special case of the PLM with $\Gamma=1$ provides a simple model for predicting aqueous dissolution for aged sites. A high quality partitioning tracer test is a good approach to estimate the parameters of the EST model, however, the model parameters can also be estimated through a combination of multiple data sets such as nonpartitioning tracer (assume $\sigma_{\ln \tau}=\sigma_{\ln t}$ ), push-pull tracers (mass and $\sigma_{\ln \tau}$ ), and soil cores (mass). Data often collected in the early phase of site investigation, such as soil cores, MIP, PFMs and MLS can be used to delineate and confirm the location and extent of the source zone. These data can also be used to estimate the source mass which is needed for dissolution models. Combining all characterization information can lead to improved parameterization of the EST model. 
The contaminated fraction, $f_{c}$, and DNAPL volume in the source zone are important for either the EST or PLM to accurately predict aqueous dissolution. The $f_{c}$ should be estimated when steady state dissolution is approached estimated using the capture time. Accuracy of volume estimates strongly affects SSF parameterization. Here, we arrive at different SSFs due to different DNAPL volume estimates and based on different methods employing field data. Partitioning tracer data with a low retardation factor (less than 1.2) can lead to higher volume estimation uncertainties. High resolution soil core data can provide a reasonable range of volume estimates and guide subsequent remediation. Local partitioning tracer peak loss compared to nonpartitioning tracer may be directly responsive to local DNAPL and was used for the MLS data and suggested more DNAPL present, particularly in the low-flow zone. While the presence of the additional mass has high uncertainty, the MLS data could have high value for improved characterization of mass located in low-flow zones. MLS data can lead to estimates of the percentage of mass discharge associated with low-flow zones, at Alameda $67 \%$ of the mass discharge was estimated to be from the low-flow zone. The volume estimate from a push-pull tracer test may have uncertainty due to an often limited swept volume compared to entire source zone.

At sites where DNAPL is located in a low permeability zone, it is important to target the DNAPL contaminated zone to improve remedial efficiency. A longer flushing duration may be required to ensure that water flows through the low-flow zone and that contaminant mass is removed (Hayden et al., 2006). At these sites, MLS data may be critical to identify the presence of DNAPL in low-flow zones and improve our understanding of long term dissolution. 


\section{Acknowledgements}

This study was funded by US Navy and SERDP, which is a collaborative effort involving the U.S.EPA, U.S.DOE, and U.S.DOD. This document has not been subjected to peer review within these agencies and the conclusions stated here do not necessarily reflect official views of these agencies, nor does this document constitute an official endorsement by these agencies. The authors thank two anonymous reviewers, whose detailed comments helped improve the quality of the manuscript.

Table 1. Well screen intervals and radius information in the source zone

\begin{tabular}{cccc}
\hline Well & Screen Interval (m bgs) & bottom & $\begin{array}{c}\text { Diameter } \\
(\mathrm{cm})\end{array}$ \\
\hline SIW-01 through 03 & 4.6 & 7.6 & 10 \\
MLS-1through 8 & 5.0 & 7.0 & 3.8 \\
PEW-01through 04 & 4.6 & 7.6 & 10 \\
SPW-1, SPW-2 & 5.2 & 6.7 & 3.8 \\
SPW-3-1 & 5.2 & 5.9 & 3.8 \\
SPW-3-2 & 5.9 & 6.7 & 3.8 \\
SPW-4 & 5.2 & 6.7 & 3.8 \\
MW1A1 & 5.2 & 5.9 & 5.1 \\
\hline
\end{tabular}


Table 2. Tracer partitioning coefficient $\mathrm{K}_{\mathrm{N}}\left(\mathrm{TCE}\right.$-water) and input concentration $\mathrm{C}_{0}$ for the push-pull tracer test and partitioning tracer test (PTT).

\begin{tabular}{clcc}
\hline & Tracers & $\mathrm{K}_{\mathrm{N}}$ & $\mathrm{C}_{0}(\mathrm{mg} / \mathrm{L})$ \\
\hline & methanol & 0 & 530 \\
& IPA & 0 & 1050 \\
Push pull & n-hexanol & 21 & 470 \\
tracer test & DMP & 63 & 540 \\
& e-HEX & 280 & 130 \\
& 1-octonal & 421 & 130 \\
\hline$---m e t h a n o l$ & 0 & 430 \\
Partitioning & IPA & 0 & 1000 \\
tracer test & n-hexanol & 99 & 380 \\
(PTT) & 2-octonal & 266 & 120 \\
& e-HEX & 280 & 120 \\
\hline
\end{tabular}


Table 3. NAPL volume estimates using four methods including swept volume, NAPL saturation and total volumes.

\begin{tabular}{|c|c|c|c|c|c|}
\hline \multirow{3}{*}{ Method 1} & & $V_{\text {soil }}\left(\mathrm{m}^{3}\right)$ & $V_{N}(\mathrm{~L})$ & & \\
\hline & $\min$ & 4.0 & 2.0 & & \\
\hline & $\max$ & 40 & 20 & & \\
\hline \multirow{6}{*}{ M2 } & & $V_{S}\left(\mathrm{~m}^{3}\right)$ & $R$ & $\bar{S}_{N}$ & $V_{N}(\mathrm{~L})$ \\
\hline & PEW-01 & 15 & 1.05 & 1.99E-04 & 3.0 \\
\hline & PEW-02 & 12 & 1.12 & 4.74E-04 & 5.8 \\
\hline & PEW-03 & 10 & 1.06 & $2.48 \mathrm{E}-04$ & 2.5 \\
\hline & PEW-04 & 12 & 1.00 & $5.27 \mathrm{E}-06$ & 0.06 \\
\hline & PEW-T & 49 & 1.06 & 2.32E-04 & 11 \\
\hline \multirow{2}{*}{ M3 } & & $f_{c}$ & $m_{1}^{\hat{S}}$ & $V_{S}\left(\mathrm{~m}^{3}\right)$ & $V_{N}(\mathrm{~L})$ \\
\hline & SPW-3-1 & 0.14 & $2.11 \mathrm{E}-03$ & 12 & 3.7 \\
\hline \multirow{6}{*}{ M4-1 } & & $V_{S}\left(\mathrm{~m}^{3}\right)$ & $\bar{S}_{N}$ & $V_{N}(\mathrm{~L})$ & \\
\hline & PEW-01 & 15 & $1.38 \mathrm{E}-04$ & 2.1 & \\
\hline & PEW-02 & 12 & 4.49E-04 & 5.4 & \\
\hline & PEW-03 & 10 & $2.06 \mathrm{E}-04$ & 2.1 & \\
\hline & PEW-04 & 12 & $2.92 \mathrm{E}-05$ & 0.35 & \\
\hline & sum & 49 & & 9.9 & \\
\hline \multirow{14}{*}{ M4-2 } & & $V_{S}\left(\mathrm{~m}^{3}\right)$ & $\bar{S}_{N}$ & $V_{N}(\mathrm{~L})$ & \\
\hline & MLS-4-1 & 1.15 & 0 & 0 & \\
\hline & MLS-4-2 & 1.15 & $4.25 \mathrm{E}-03$ & 4.9 & \\
\hline & MLS-4-3 & 1.15 & $9.35 \mathrm{E}-03$ & 11 & \\
\hline & MLS-4-4 & 1.15 & $2.86 \mathrm{E}-04$ & 0.33 & \\
\hline & MLS-7-1 & 0.60 & 7.33E-03 & 4.4 & \\
\hline & MLS-7-2 & 0.60 & $9.24 \mathrm{E}-03$ & 5.5 & \\
\hline & MLS-7-3 & 0.60 & $6.08 \mathrm{E}-03$ & 3.6 & \\
\hline & MLS-7-4 & 0.60 & 0 & 0 & \\
\hline & MLS-8-1 & 0.30 & $9.96 \mathrm{E}-03$ & 3.0 & \\
\hline & MLS-8-2 & 0.30 & $9.37 \mathrm{E}-03$ & 2.8 & \\
\hline & MLS-8-3 & 0.30 & $6.81 \mathrm{E}-03$ & 2.0 & \\
\hline & MLS-8-4 & 0.30 & 0 & 0 & \\
\hline & sum & 8.17 & & 37 & \\
\hline
\end{tabular}


Table 4. EST model parameters and volume in the swept volume for each individual extraction well and flux averaged for all wells. The results are based on the best fit of the enhanced dissolution data (mass discharge) with the EST model using a generic algorithm code. Included are coefficient of efficiency (E), three EST model parameters $\left(f_{\mathrm{c}}, \mu_{\ln \tau}\right.$ and $\left.\sigma_{\ln \tau}\right)$ and estimated volume in the form of mean \pm standard deviation.

\begin{tabular}{cccccc}
\hline & $\mathrm{E}$ & $f_{\mathrm{c}}$ & $\mu_{\ln \tau}$ & $\sigma_{\ln \tau}$ & $V_{N}(\mathrm{~L})$ \\
\hline PEW-1 & $0.93 \pm 0.00$ & $0.016 \pm 0.000$ & $3.50 \pm 0.02$ & $1.32 \pm 0.06$ & $2.6 \pm 0.3$ \\
PEW-2 & $0.80 \pm 0.01$ & $0.024 \pm 0.001$ & $3.85 \pm 0.09$ & $1.33 \pm 0.16$ & $5.5 \pm 1.2$ \\
PEW-3 & $0.92 \pm 0.01$ & $0.010 \pm 0.000$ & $3.60 \pm 0.06$ & $1.47 \pm 0.14$ & $2.1 \pm 0.3$ \\
PEW-4 & 0 & 0.001 & 5.0 & 0.20 & 0.49 \\
Sum $^{*}$ & & & & & $11 \pm 1.8$ \\
PEW-total $^{* *}$ & $0.90 \pm 0.00$ & $0.013 \pm 0.000$ & $3.66 \pm 0.05$ & $1.41 \pm 0.02$ & $11 \pm 0.8$ \\
\hline
\end{tabular}

* Sum represents adding volume from individual best fit for each extraction well;

** PEW-total used flux average mass discharge data from the four extraction wells to fit EST model and obtained volume directly. 
Table 5. PLM parameters and volume of DNAPL in the swept volume for each individual extraction well and flux averaged of all wells. The results are the best fit of the enhanced dissolution data (mass discharge) with the PLM using a generic algorithm. Included are coefficient of efficiency (E), three PLM model parameters $\left(f_{\mathrm{c}}\right.$ and $\left.\Gamma\right)$ and estimated volume in the form of mean \pm standard deviation.

\begin{tabular}{ccccc}
\hline & $\mathrm{E}$ & $f_{\mathrm{c}}$ & $\Gamma$ & $V_{N}(\mathrm{~L})$ \\
\hline PEW-1 & $0.94 \pm 0.00$ & $0.016 \pm 0.000$ & $1.06 \pm 0.11$ & $1.9 \pm 0.1$ \\
PEW-2 & $0.81 \pm 0.00$ & $0.026 \pm 0.000$ & $0.94 \pm 0.08$ & $3.1 \pm 0.2$ \\
PEW-3 & $0.92 \pm 0.00$ & $0.010 \pm 0.000$ & $2.44 \pm 0.54$ & $2.2 \pm 0.6$ \\
PEW-4 & 0.0 & 0.002 & 0.01 & 0.49 \\
Sum $^{*}$ & & & & $7.7 \pm 0.9$ \\
PEW-total $^{* *}$ & $0.90 \pm 0.00$ & $0.013 \pm 0.000$ & $1.28 \pm 0.06$ & $7.8 \pm 0.3$ \\
\hline
\end{tabular}

"Sum represents adding volume from individual best fit for each extraction well;

** PEW-total used flux average mass discharge data from the four extraction wells to fit PLM model and obtained volume directly. 


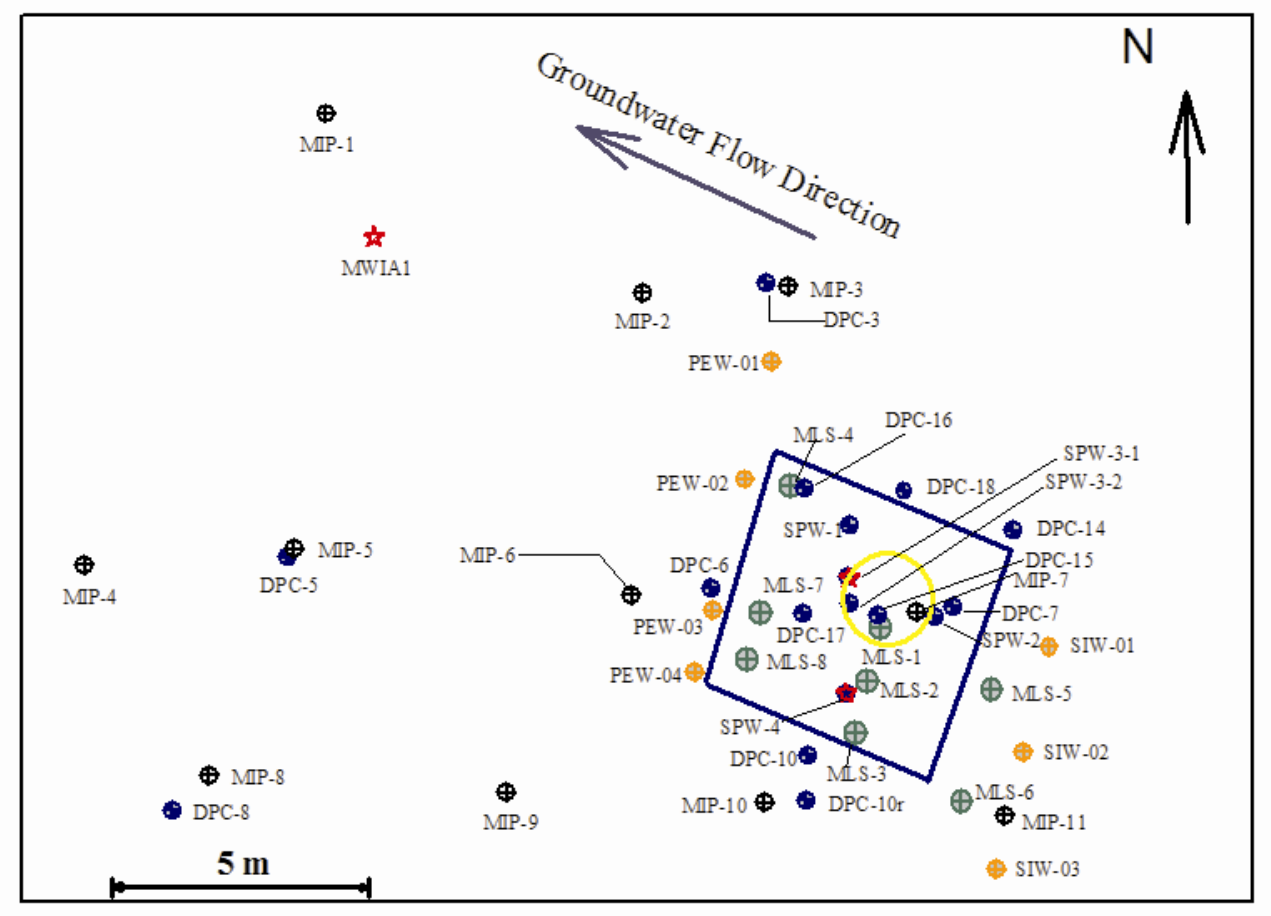

$\begin{array}{llll} & \text { Injection or Extraction Well } & \oplus \text { Multi-Level Sampler } \\ - & \text { Soil Core } & \text { \& } & \text { Push-pull Tracer Test Location } \\ & \text { MIP } & & \end{array}$

Figure 1. DNAPL source zone and field activities. Soil cores at locations of PEW-03, SMLS-1, SMLS-2 and SIW-02 were also collected at locations where there were high PID signals. Note: dark blue square indicates the suspected source zone area, and yellow circle shows the minimum extent of TCE distribution with radius $1.2 \mathrm{~m}$ and thickness $1.4 \mathrm{~m}$. 

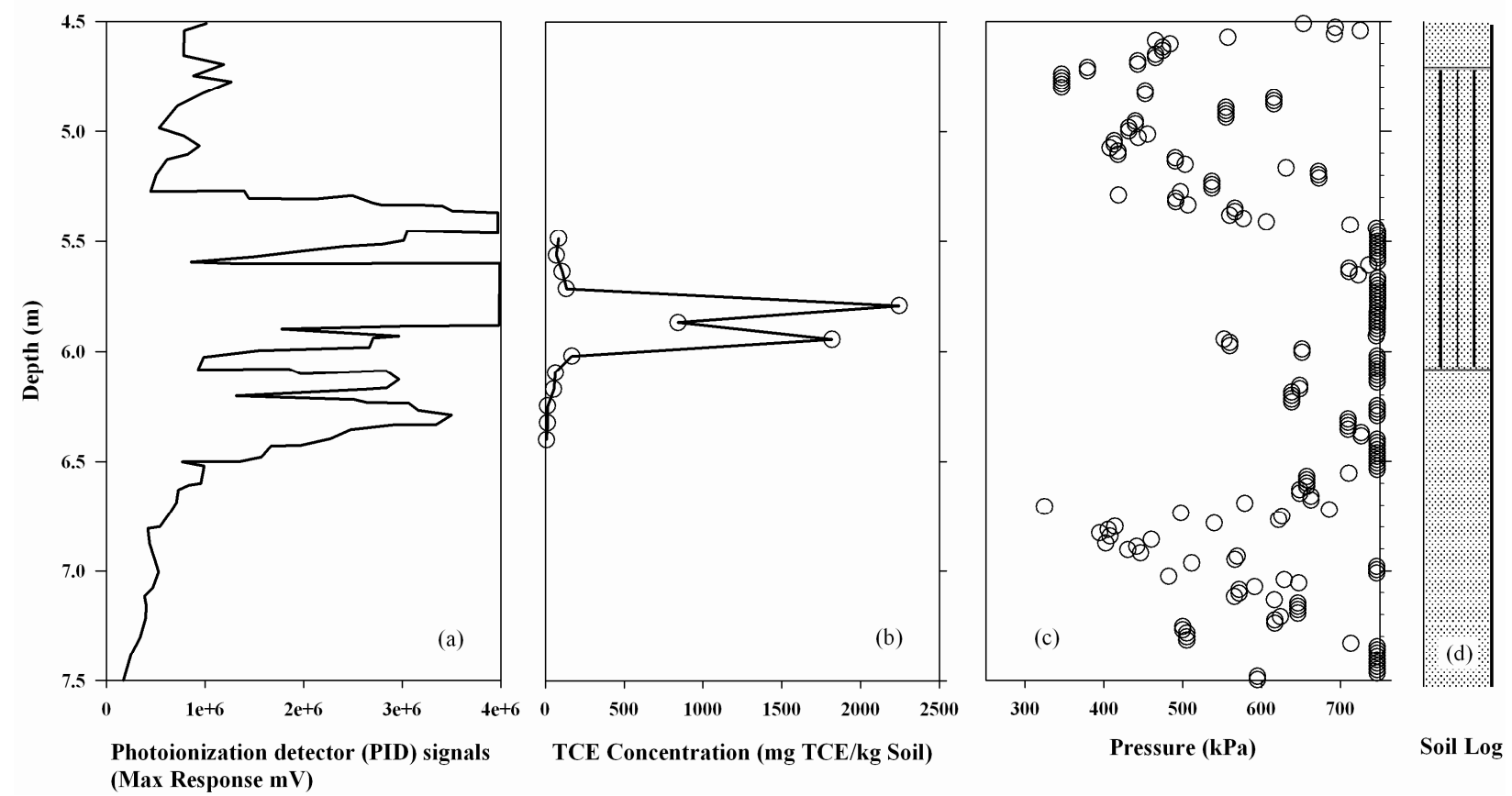

Figure 2. High DNAPL zone (a) MIP -7; (b) Soil core data at location SPW-3-2; (c) pressure from a hydraulic profiling tool (HPT) located in the source zone; (d) soil boring log located in the source zone. These four locations are close and show a high DNAPL zone at the depth of 5.2 $\mathrm{m}$ to $6.1 \mathrm{~m}$ within a low-flow zone. For the soil $\mathrm{log}$, the center part with vertical lines represents $85 \%$ sand and $15 \%$ silt, while the two end parts represent sand. 


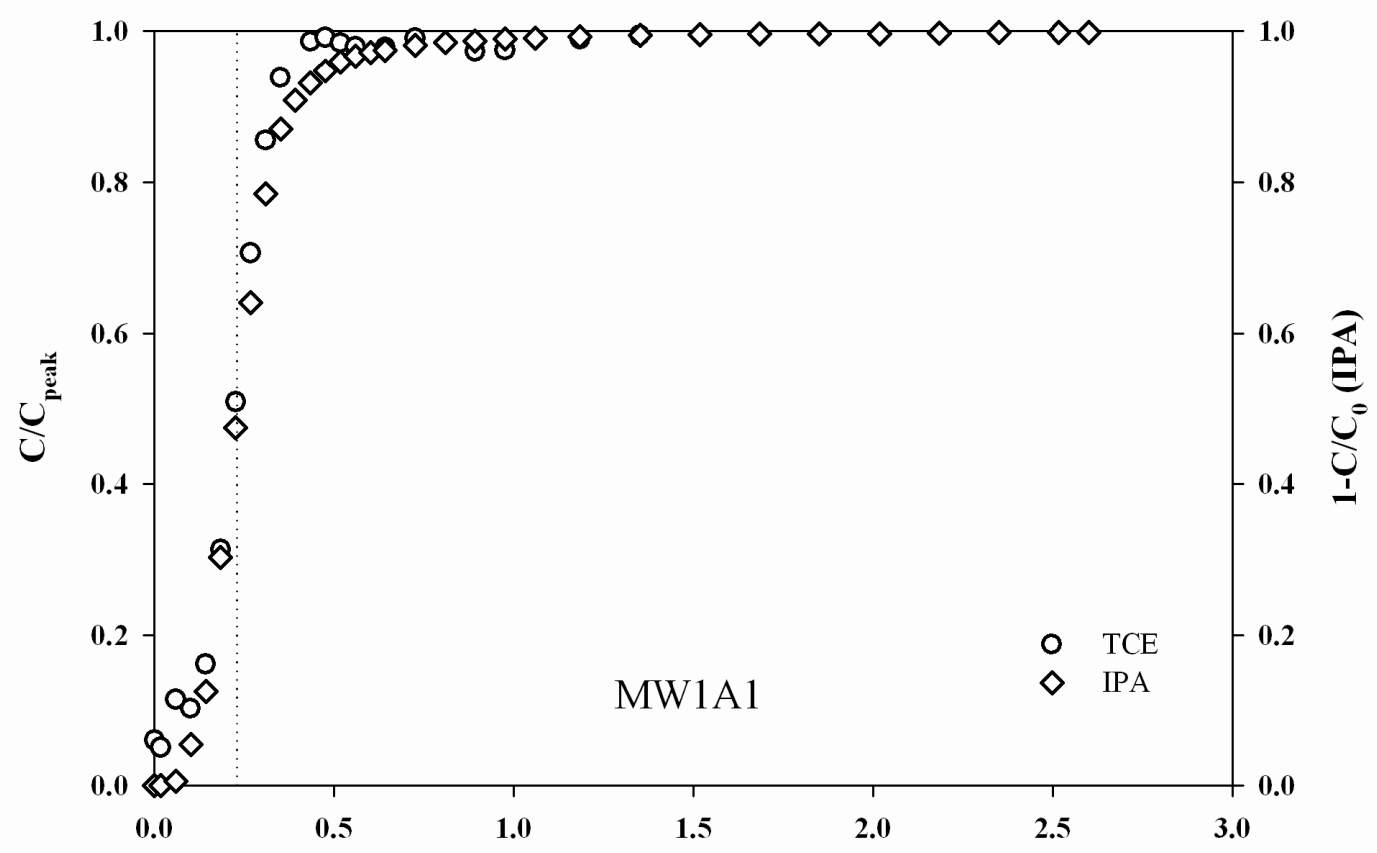

Time (days)

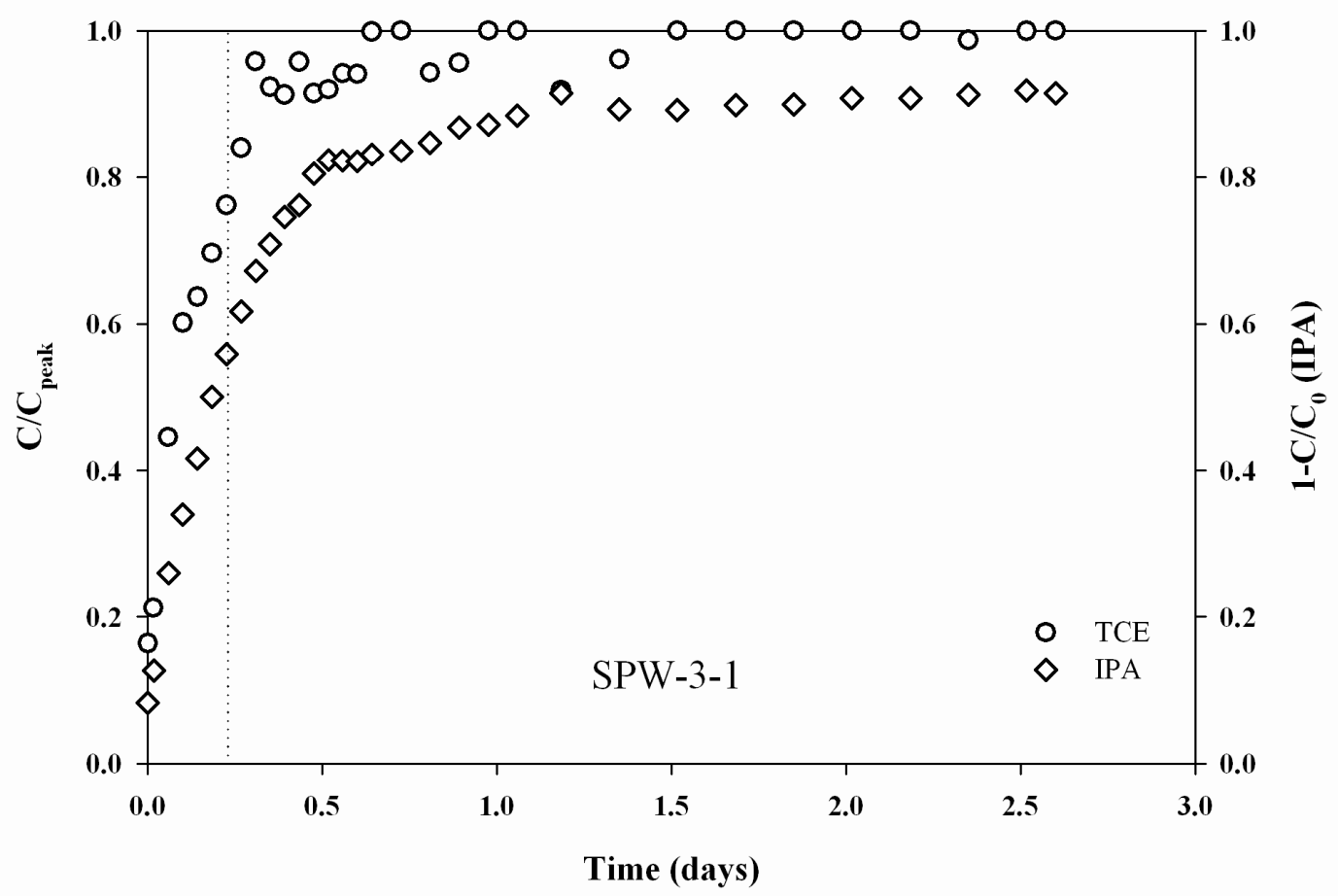

Figure 3. Arrival time comparisons between aqueous TCE and nonpartitioning tracer IPA during push-pull tracer test. The well MW1A1 is located in the plume and the well SPW-3-1 is located in the source zone. The dotted line represents the time when the injected volume was pumped out. 


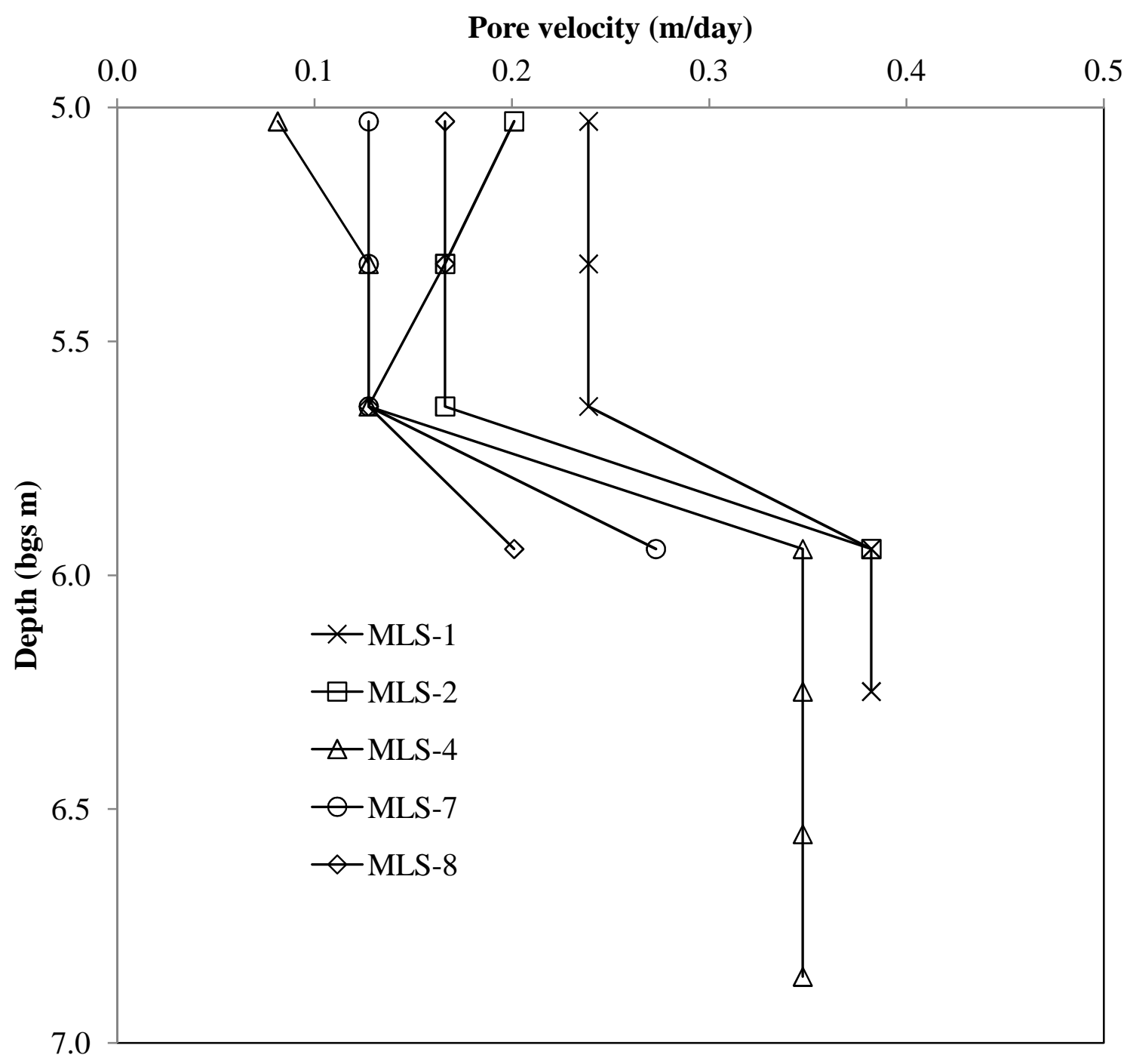

Figure 4. Pore velocity (m/day) versus depth for MLSs in the source zone during the PTT period. Pore velocity was calculated based on the distance from tracer release plane (SIWs) and nonpartitioning tracer (methanol) peak arrival times without considering tortuosity. 


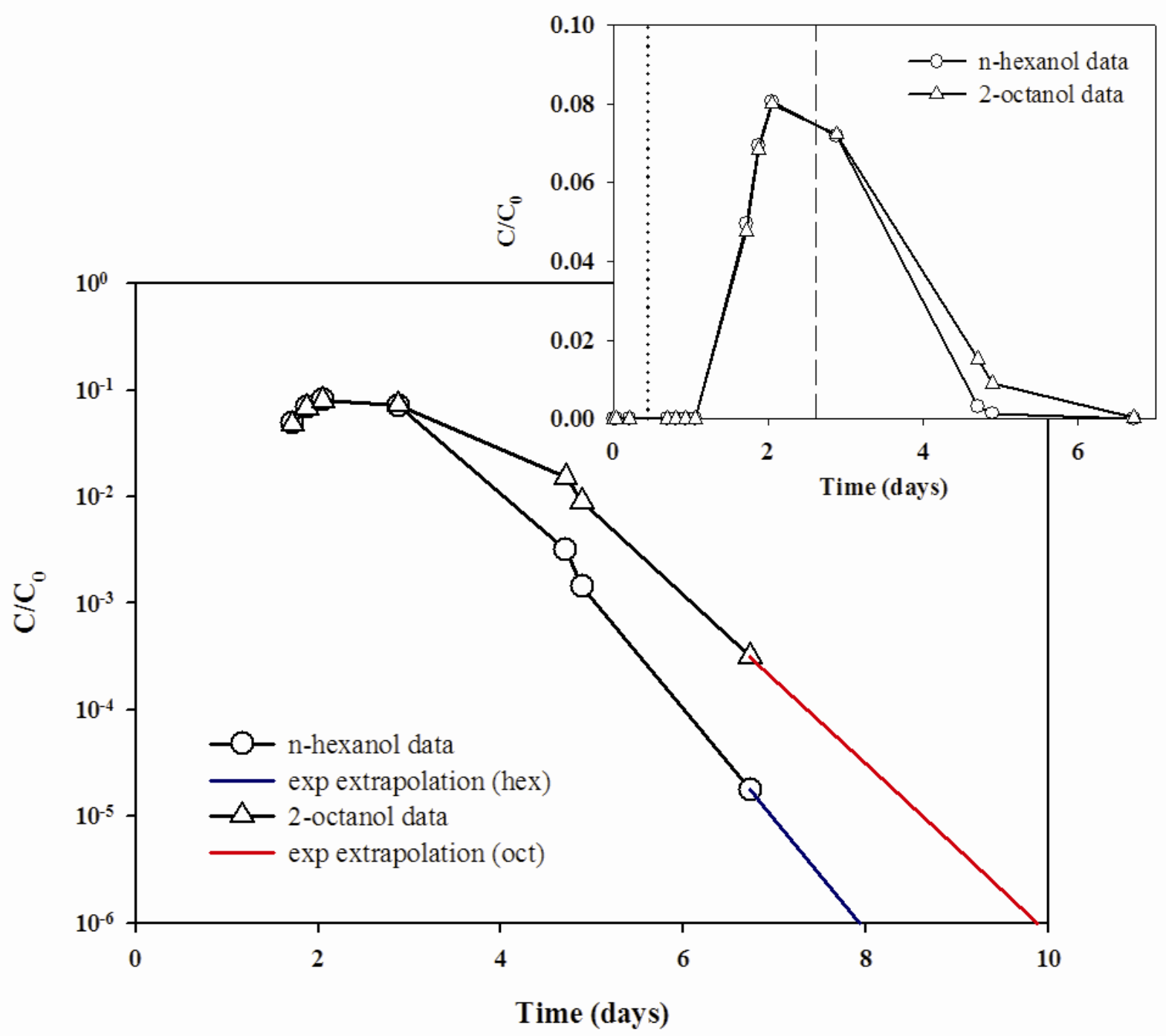

Figure 5. Partitioning tracer breakthrough curves for $n$-hexanol and 2-octonal linear scale (upper graph) and in the log scale (lower graph) with exponential extrapolations for the flow-weighted average $\mathrm{PEW}_{\mathrm{T}}$. The dotted vertical line represents the end of tracer injection. The dashed vertical line represents the average travel time for $\mathrm{n}$-hexanol. 


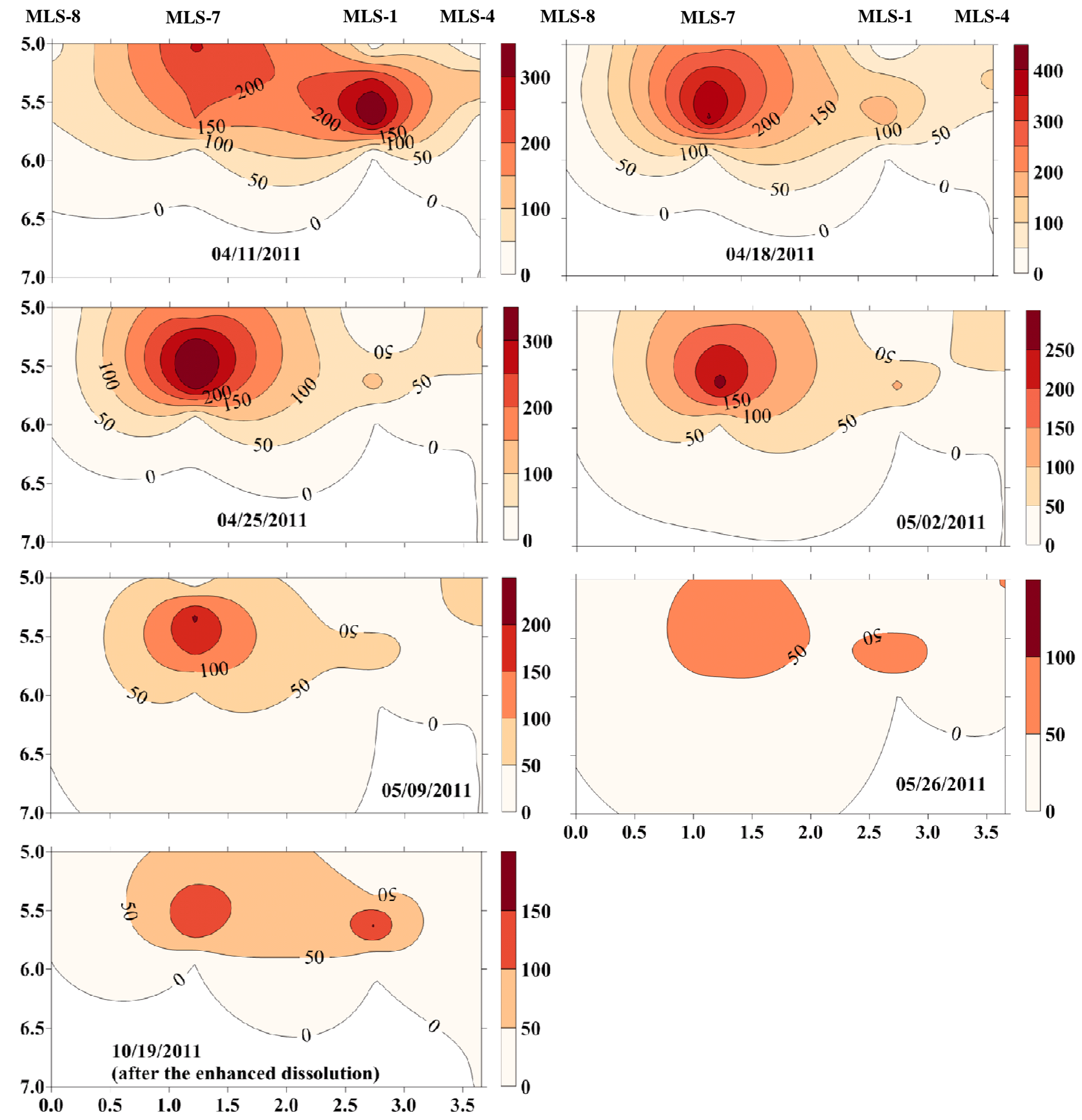

Figure 6. Aqueous TCE concentration during the enhanced dissolution and after the enhanced dissolution at MLS-1, 4, 7, 8 transect. 


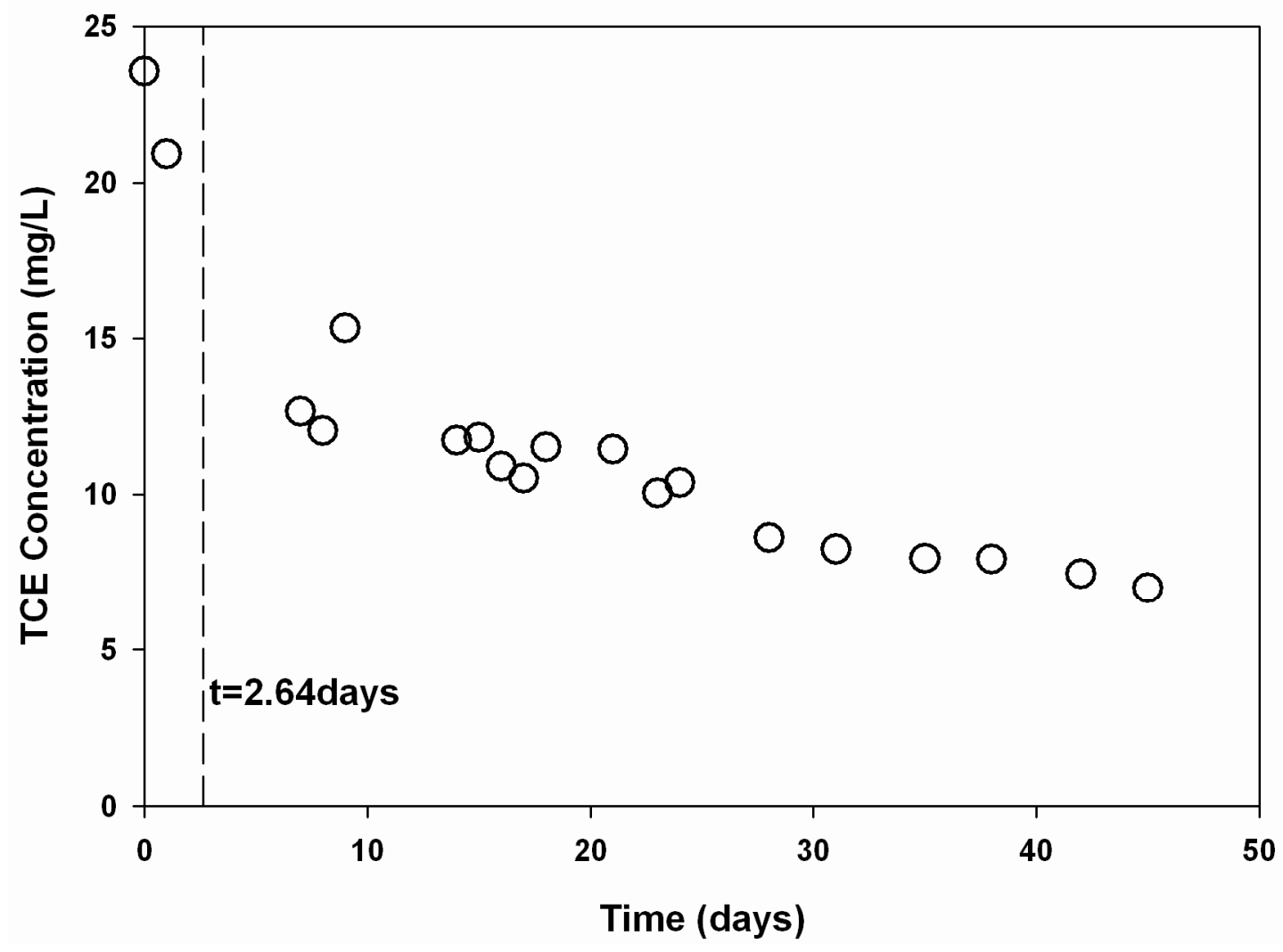

Figure 7. Flux average TCE concentration from the four extraction wells with the capture time (2.64days) indicated when the flow field approached steady state. 

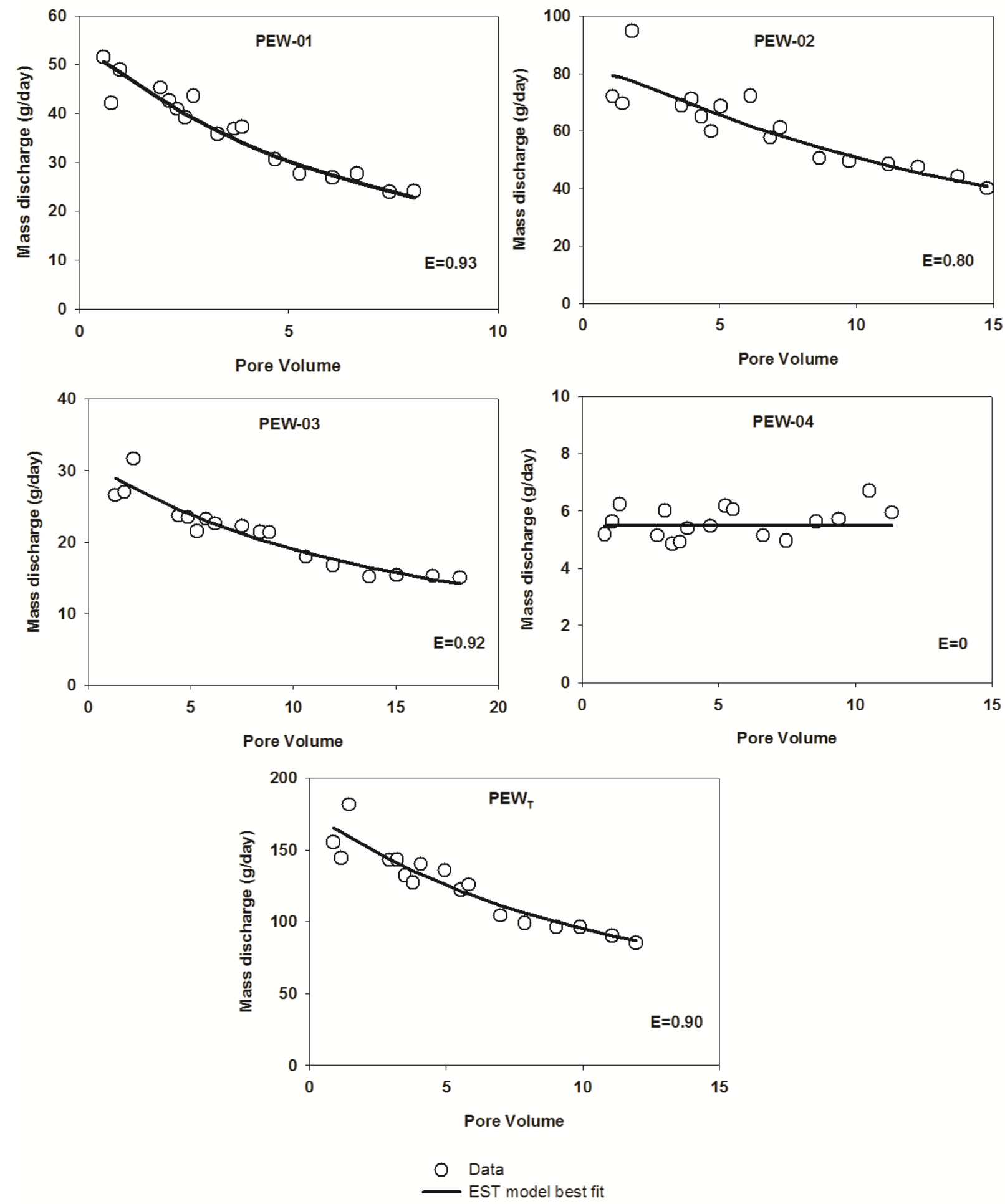

Figure 8. EST model best fit for enhanced dissolution data. Note: the pore volume zero represents the date for groundwater sampling before the enhanced dissolution. 


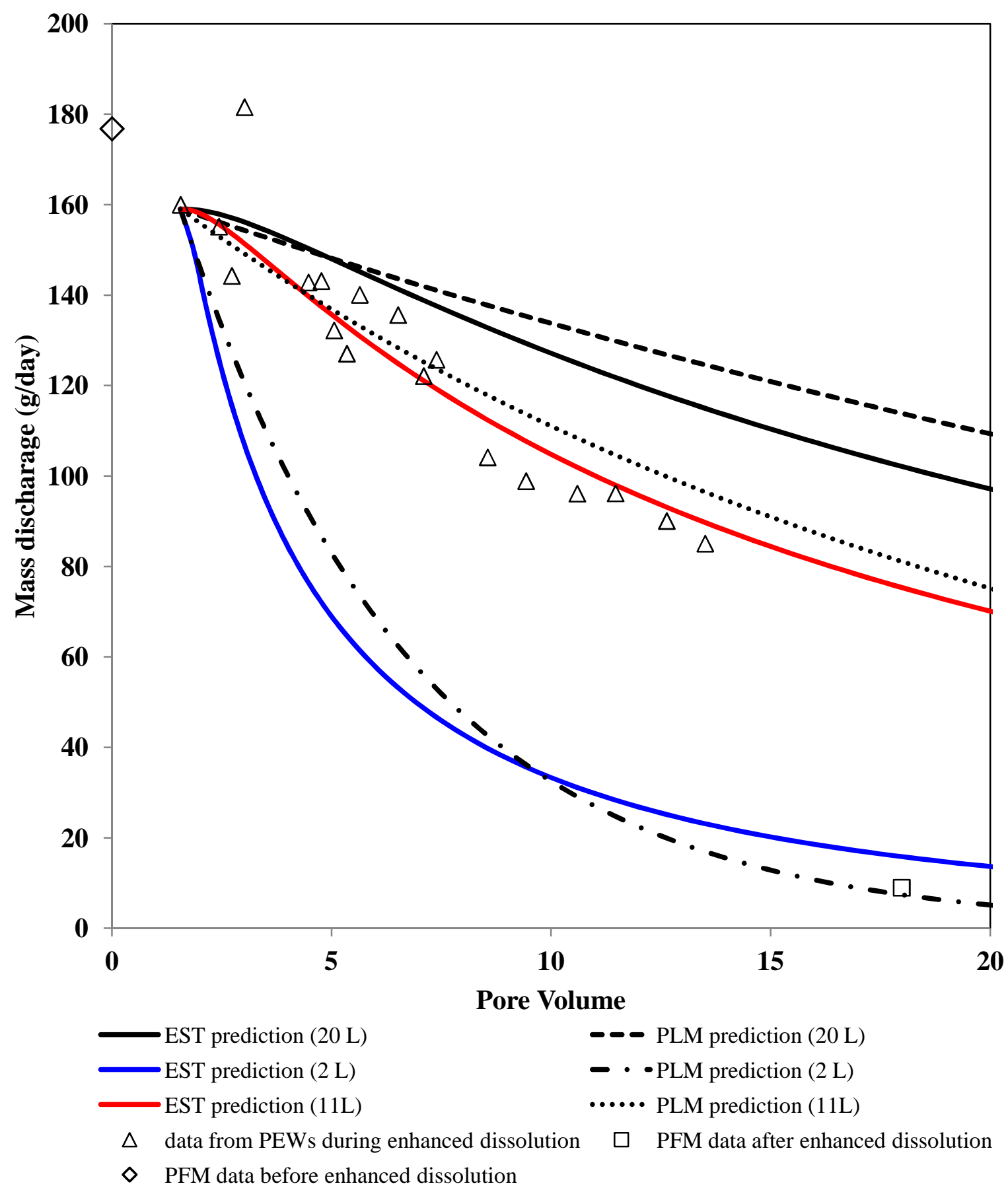

Figure 9. Aqueous dissolution predictions by combining soil core data, MIP data, Push-Pull tracer data and PTT data for both EST and PLM models. Passive flux meter (PFM) data before enhanced dissolution (diamond symbol) and after enhanced dissolution (square symbol) were plotted. 
Annable, M.D. et al., 2005. Field-scale evaluation of the passive flux meter for simultaneous measurement of groundwater and contaminant fluxes. Environmental science \& technology, 39(18): 7194-7201.

Annable, M.D. et al., 1998. Partitioning tracers for measuring residual NAPL: Field-scale test results. Journal of Environmental Engineering, 124(6): 498-503.

Basu, N.B., Fure, A.D. and Jawitz, J.W., 2008a. Predicting dense nonaqueous phase liquid dissolution using a simplified source depletion model parameterized with partitioning tracers. Water Resources Research, 44(7): W07414.

Basu, N.B., Fure, A.D. and Jawitz, J.W., 2008b. Simplified contaminant source depletion models as analogs of multiphase simulators. Journal of contaminant hydrology, 97(3): 87-99.

Brewster, M.L. et al., 1995. Observed migration of a controlled DNAPL release by geophysical methods. Groundwater, 33(6): 977-987.

Bronders, J., Van Keer, I., Touchant, K., Vanermen, G. and Wilczek, D., 2009. Application of the membrane interphase probe (MIP): an evaluation. Journal of Soils and Sediments, 9(1): 74-82.

Brooks, M.C. et al., 2002. Controlled release, blind tests of DNAPL characterization using partitioning tracers. Journal of contaminant hydrology, 59(3): 187-210.

Cain, R.B., Johnson, G.R., McCray, J.E., Blanford, W.J. and Brusseau, M.L., 2000. Partitioning tracer tests for evaluating remediation performance. Ground Water, 38(5): 752-761.

Chen, X. and Jawitz, J.W., 2008. Reactive Tracer Tests To Predict Dense Nonaqueous Phase Liquid Dissolution Dynamics in Laboratory Flow Chambers. Environmental science \& technology, 42(14): 5285-5291.

Chen, X. and Jawitz, J.W., 2009. Convergence of DNAPL source strength functions with site age. Environmental science \& technology, 43(24): 9374-9379.

Christ, J.A., 2005. A numerical investigation of metabolic reductive dechlorination in DNAPL source zones, DTIC Document.

Christ, J.A., Ramsburg, C.A., Pennell, K.D. and Abriola, L.M., 2006. Estimating mass discharge from dense nonaqueous phase liquid source zones using upscaled mass transfer coefficients: An evaluation using multiphase numerical simulations. Water Resources Research, 42(11).

Christ, J.A., Ramsburg, C.A., Pennell, K.D. and Abriola, L.M., 2010. Predicting DNAPL mass discharge from pool-dominated source zones. Journal of contaminant hydrology, 114(1): 18-34.

Dekker, T.J. and Abriola, L.M., 2000. The influence of field-scale heterogeneity on the infiltration and entrapment of dense nonaqueous phase liquids in saturated formations. Journal of contaminant hydrology, 42(2): 187-218.

DiFilippo, E.L. and Brusseau, M.L., 2008. Relationship between mass-flux reduction and source-zone mass removal: Analysis of field data. Journal of contaminant hydrology, 98(1): 22-35.

Falta, R.W., Basu, N. and Rao, P.S., 2005a. Assessing impacts of partial mass depletion in DNAPL source zones: II. Coupling source strength functions to plume evolution. Journal of Contaminant Hydrology, 79(1): 45-66.

Falta, R.W. et al., 1999. Field test of high molecular weight alcohol flushing for subsurface nonaqueous phase liquid remediation. Water Resources Research, 35(7): 2095-2108.

Falta, R.W., Stacy, M.B., Ahsanuzzaman, N.A., Wang, M. and Earle, R.C., 2007. REMChlor: Remediation evaluation model for chlorinated solvents, User's Manual Version 1.0. Cent. for Subsurface Model. Support, US Environ. Prot. Agency, Ada, Okla.

Falta, R.W., Suresh Rao, P. and Basu, N., 2005b. Assessing the impacts of partial mass depletion in DNAPL source zones: I. Analytical modeling of source strength functions and plume response. Journal of Contaminant Hydrology, 78(4): 259-280.

Feenstra, S., 2003. Spatial Variability of Non-Aqueous Phase Liquid Chemicals in Soilâ€"Implications for Source Zone Mass Estimates. Environmental \& Engineering Geoscience, 9(1): 19-23. 
Fure, A.D., Jawitz, J.W. and Annable, M.D., 2006. DNAPL source depletion: Linking architecture and flux response. Journal of contaminant hydrology, 85(3): 118-140.

Hartog, N., Cho, J., Parker, B.L. and Annable, M.D., 2010. Characterization of a heterogeneous DNAPL source zone in the Borden aquifer using partitioning and interfacial tracers: Residual morphologies and background sorption. Journal of Contaminant Hydrology, 115(1-4): 79-89.

Hatfield, K., Annable, M., Cho, J., Rao, P.S.C. and Klammler, H., 2004. A direct passive method for measuring water and contaminant fluxes in porous media. Journal of Contaminant Hydrology, 75(3): 155-181.

Hayden, N., Diebold, J., Farrell, C., Laible, J. and Stacey, R., 2006. Characterization and removal of DNAPL from sand and clay layered media. Journal of contaminant hydrology, 86(1): 53-71.

ITRC (Interstate Technology \& Regulatory Council). 2011. Integrated DNAPL Site Strategy. IDSS-1. Washington, DC: Interstate Technology \& Regulatory Council, Integrated DNAPL Site Strategy Team.

Jawitz, J.W., Annable, M.D., Demmy, G.G. and Rao, P.S.C., 2003. Estimating nonaqueous phase liquid spatial variability using partitioning tracer higher temporal moments. Water Resour. Res, 39(7): 1192.

Jawitz, J.W., Fure, A.D., Demmy, G.G., Berglund, S. and Rao, P.S.C., 2005. Groundwater contaminant flux reduction resulting from nonaqueous phase liquid mass reduction. Water Resources Research, 41(10): W10408.

Jawitz, J.W., Sillan, R.K., Annable, M.D., Rao, P.S.C. and Warner, K., 2000. In-situ alcohol flushing of a DNAPL source zone at a dry cleaner site. Environmental science \& technology, 34(17): 37223729.

Jin, M. et al., 1995. Partitioning tracer test for detection, estimation, and remediation performance assessment of subsurface nonaqueous phase liquids. Water Resources Research, 31(5): 12011211.

Johnston C.D., Davis G.B., Bastow, T.P., Annable, M.D. Trefry, M.G., Furness, A., Geste, Y., Woodbury, R.J., Rao, P.S.C. and Rhodes, S., 2013. The Use of Mass Depletion-Mass Flux Reduction Relationships During Pumping to Determine Source Zone Mass of a Reactive Brominated-Solvent DNAPL. Journal of Contaminant Hydrology, 144, 122-137.

Kubert, M. and Finkel, M., 2006. Contaminant mass discharge estimation in groundwater based on multi-level point measurements: A numerical evaluation of expected errors. Journal of Contaminant Hydrology, 84(1): 55-80.

Meinardus, H.W. et al., 2002. Performance assessment of NAPL remediation in heterogeneous alluvium. Journal of Contaminant Hydrology, 54(3): 173-193.

Nadolishny, A.N. and Fraser, M.T., 2001. Membrane interface probe (MIP) for expedited DNAPL delineation, International Containment Technology Conference, Orlando/USA, June.

Nelson, N.T. and Brusseau, M.L., 1996. Field study of the partitioning tracer method for detection of dense nonaqueous phase liquid in a trichloroethene-contaminated aquifer. Environmental Science and Technology, 30(9): 2859-2863.

Page, J.W.E., Soga, K. and Illangasekare, T., 2007. The significance of heterogeneity on mass flux from DNAPL source zones: An experimental investigation. Journal of contaminant hydrology, 94(3): 215-234.

Parker, J.C. and Falta, R.W., 2008. Comparison of alternative upscaled model formulations for simulating DNAPL source dissolution and biodecay. Advances in Water Resources, 31(10): 1325-1332.

Parker, J.C., Kim, U., Widdowson, M., Kitanidis, P. and Gentry, R., 2010. Effects of model formulation and calibration data on uncertainty in dense nonaqueous phase liquids source dissolution predictions. Water Resources Research, 46(12). 
Parker, J.C. and Park, E., 2004. Modeling field-scale dense nonaqueous phase liquid dissolution kinetics in heterogeneous aquifers. Water Resources Research, 40(5): W05109.

Phelan, T.J., Lemke, L.D., Bradford, S.A., O'Carroll, D.M. and Abriola, L.M., 2004. Influence of textural and wettability variations on predictions of DNAPL persistence and plume development in saturated porous media. Advances in Water Resources, 27(4): 411-427.

Ramsburg, C.A. et al., 2005. Pilot-scale demonstration of surfactant-enhanced PCE solubilization at the Bachman Road Site. 2. System operation and evaluation. Environmental science \& technology, 39(6): 1791-1801.

Schroth, M.H., Istok, J.D. and Haggerty, R., 2000. In situ evaluation of solute retardation using single-well push-pull tests. Advances in Water Resources, 24(1): 105-117.

Stafford, B.P., CÃipiro, N.L., Alvarez, P.J.J. and Rixey, W.G., 2009. Pore water characteristics following a release of neat ethanol onto pre-existing NAPL. Ground water monitoring \& remediation, 29(3): 93-104.

Unger, A.J.A., Forsyth, P.A. and Sudicky, E.A., 1998. Influence of alternative dissolution models and subsurface heterogeneity on DNAPL disappearance times. Journal of Contaminant Hydrology, 30(3): 217-242.

Wang, F., Annable, M.D. and Jawitz, J.W., 2013. Field-scale prediction of enhanced DNAPL dissolution based on partitioning tracers. Journal of contaminant hydrology, 152: 147-158.

Wood, B.T., 2011. Estimating Source Strength Functions of Dense Non-aqueous Phase Liquids from Historical Field Datasets. Thesis, University of Florida.

Yang, Y.J., Spencer, R.D. and Gates, T.M., 1995. Analytical Solutions for Determination of Non-SteadyState and Steady-State Capture Zones. Ground Water Monitoring \& Remediation, 15(1): 101-106.

Zhu, J. and Sykes, J.F., 2004. Simple screening models of NAPL dissolution in the subsurface. Journal of Contaminant Hydrology, 72(1): 245-258. 